\title{
TOS EXPANDS EFFORTS TO PROMOTE JUSTICE, EQUITY, DIVERSITY, AND INCLUSION IN THE OCEAN SCIENCES
}

\author{
By Erin Meyer-Gutbrod, Frank Muller-Karger, and the TOS Justice, Equity, Diversity, and Inclusion Committee
}

IN LATE 2020, The Oceanography Society (TOS) established a Justice, Equity, Diversity, and Inclusion (JEDI) committee to comprehensively examine the role that TOS can play in promoting JEDI values in the ocean sciences community. The JEDI Committee's charge is to help TOS alleviate barriers to participation and shape a welcoming future for groups that have been historically marginalized in oceanography and related sciences.

An open call for volunteers led to the selection and appointment of 11 committee members (see Box 1). The committee includes international students and early career scientists and professionals. It meets semi-monthly for discussions and agenda setting. During a virtual winter retreat, committee members shared experiences and developed the committee's mission, values, vision, and mandates.

JEDI committee objectives include:

1. Guiding TOS leadership to increase access and participation of historically marginalized groups in TOS events and programming

2. Supporting and amplifying existing efforts to eliminate bias and unfair treatment in oceanography and related fields

3. Creating and sharing tools and resources for dismantling barriers to participation of historically marginalized groups at their places of work or study

4. Hosting an open and welcoming dialogue with the community to accomplish these goals

We invite the TOS membership to contribute thoughts and ideas to this process. To advance justice, equity, diversity, and inclusion in oceanography and related fields, TOS will use its outlets and tools, including TOS meetings, communication channels, and membership networks; Oceanography magazine; the biennial Ocean Sciences Meetings; and honors and awards. TOS seeks to engage other professional societies and international organizations as well. A JEDI column will be published quarterly in Oceanography to share progress and engage the TOS membership in discussions on these topics. We invite members of the community to continue to publish on this topic and to use the journal Oceanography for this purpose.

TOS is committed to supporting a community that encourages the open expression and exchange of ideas, free from all forms of discrimination, harassment, and retaliation. A welcoming, diverse community of individuals will advance oceanography more effectively than a closed community of homogeneous perspectives and backgrounds. These goals require us to dismantle systemic bias and barriers in educational systems, access to resources, hiring, promotion and retention. Additionally, we can learn and benefit from reflecting on how we shape interpersonal relations and conduct business. We envision a community of scholars, scientists, and professionals in which every member contributes actively to dismantling systemic barriers and interpersonal biases, counters aggressions, and contributes to advancing equity and inclusion of diverse people in oceanography and related fields.

Our JEDI work will require consistent and thoughtful actions and continuous evaluation. While we work to establish mechanisms to receive community input and support discussion, you can connect with the JEDI committee or the TOS Council directly. For additional information, please join us on social media or visit our website (see Box 2).

\section{BOX 1. JEDI COMMITTEE MEMBERS}

Susanne Craig (co-chair), NASA Goddard Space Flight Center/USRA Beth Orcutt (co-chair), Bigelow Laboratory for Ocean Sciences Mona Behl, University of Georgia Sea Grant EeShan Bhatt, MIT/WHOI Joint Program Dick Crout, Naval Research Laboratory Erin Meyer-Gutbrod, University of South Carolina Frank Muller-Karger, University of South Florida Tashiana Osborne, Scripps Institution of Oceanography Charitha Pattiaratchi, The University of Western Australia James Pierson, University of Maryland Center for Environmental Science Amber Shearer, Garden School Foundation

\section{BOX 2. STAY IN TOUCH}

Twitter: @TOSOceanography Facebook: @OceanographySociety Instagram: @tosoceanography Website: https://tos.org/diversity Email: JEDIcochairs@tos.org 